\title{
O futuro da Pós-Graduação no Brasil em 2030
}

\author{
The future of Brazil Graduate Studies in 2030
}

\author{
João Carlos de Amorim ${ }^{\mathrm{I}}$ \\ Sheila Serafim da Silva ${ }^{\text {II }}$ \\ Renata Giovinazzo Spers ${ }^{\text {III }}$
}

\section{Resumo}

A pós-graduação no Brasil apresentou crescimento expressivo nos últimos dez anos e este fato justifica o interesse em pesquisar quais são as tendências da pós-graduação para o ano 2030. Para isso, realizou-se uma consulta com 18 especialistas em educação por meio da técnica Delphi. Os resultados receberam tratamento estatístico e qualitativo. Os resultados indicaram tendências associadas à internacionalização, ao uso de tecnologias na educação superior, o foco em produções científicas de melhor qualidade e a necessidade de mais investimento governamental. Concluiu-se que o estudo atendeu ao objetivo proposto, sendo possível analisar as tendências do futuro da Pós-Graduação do país.

Palauras-chave: Pós-Graduação no Brasil; Prospecção; Técnica Delphi.

\begin{abstract}
Graduate studies in Brazil have shown significant growth in the last ten years, and this fact justifies the interest in researching the trends of graduate studies for the year 2030. For this, a consultation with 18 education specialists was carried out through the Delphi technique. The results received statistical and qualitative treatment. The results indicated trends associated with internationalization, the use of technologies in higher education, the focus on better quality scientific production, and more government investment. It was concluded that the study met the proposed objective, and it is possible to analyze the trends of the future of Postgraduate Studies in the country.

Keywords: Graduate Studies in Brazil; Prospection; Delphi technique.
\end{abstract}

I E-mail: joao_amorim@id.uff.br, Universidade Federal Fluminense, Niterói/RJ [Brasil]

(D) ORCID Id: https://orcid.org/0000-0002-8320-2622

II E-mail: sheila_serafim@yahoo.com.br, Faculdade FIA de Administração e Negócios, São Paulo/SP [Brasil].

(D) ORCID Id: https://orcid.org/0000-0002-7104-003X

III E-mail: renatag@usp.br, Universidade de São Paulo - FEA-USP, São Paulo/SP [Brasil].

(D) ORCID Id: https://orcid.org/0000-0003-1240-0530

Recebido em: 01/07/2019

Aprovado em: 01/09/2020

\section{Revista Administração em Diálogo}

ISSN 2178-0080

Programa de Estudos Pós-Graduados em Administração

Pontifícia Universidade Católica de São Paulo 


\section{Introdução}

A pós-graduação no Brasil possui uma história recente. Esta foi implantada pelo Parecer 977 de I965 (CAPES, I965). Os cursos de pós-graduação no país tiveram início com o apoio do Ministério da Educação e Cultura (MEC) que estava interessado em formar recursos humanos altamente capacitados para o exercício do magistério superior e de pesquisadores em diversas áreas do conhecimento. Na ocasião, os docentes que ministravam aulas nos cursos de graduação no Brasil eram, em sua maioria, convidados oriundos de instituições estrangeiras.

No Brasil, a pós-graduação é gerenciada pela Coordenação de Aperfeiçoamento de Pessoal de Nível Superior (CAPES), fundação do Ministério da Educação, que desempenha um papel fundamental na expansão e consolidação de cursos de mestrado e doutorado no país, incluindo a avaliação da pós-graduação stricto sensu, o acesso e divulgação da produção científica, o investimento na formação de recursos de alto nível no país e no exterior, a promoção da cooperação científica internacional, a indução e fomento da formação inicial e continuada de professores para a educação básica nos formatos presencial e a distância (Capes, 20I9).

O crescimento da pós-graduação no país contribui para o desenvolvimento da ciência e da tecnologia (Dantas, 2004). De 2007 a 2017, o número de programas de pós-graduação no país, incluindo cursos de mestrado acadêmico e profissional e doutorado, aumentou aproximadamente $78 \%$, enquanto o número de discentes matriculados aumentou 96\%, segundo dados do Sistema de Informações Georreferenciadas (Geocapes, 2019). Cabe mencionar que os mestrados profissionais são os principais responsáveis por essa expansão.

Dado a relevante expansão quantitativa da pós-graduação no país em um contexto de grandes transformações na sociedade da informação e do conhecimento em que o acesso a ambos se tornou mais amplo e global por meio dos meios de comunicação que evoluíram sobremaneira, ampliando ainda a interação e a colaboração na sociedade. Nesse contexto, torna-se relevante conhecer para onde caminha a pósgraduação no Brasil.

Conhecer as tendências da pós-graduação no país é muito importante, principalmente para as instituições de educação que ofertam cursos no nível superior, 
seus coordenadores e corpo docente, bem como para a CAPES e outros órgãos como o Conselho Nacional de Desenvolvimento Científico e Tecnológico (CNPq), vinculado ao Ministério da Ciência, Tecnologia, Inovações e Comunicações para incentivo à pesquisa no país. Prospectar as suas tendências permitem antecipar acontecimentos futuros, bem como contribuir para uma expansão mais bem planejada.

Todavia, qual será o futuro da pós-graduação no Brasil, considerando o ano de 2030? Para responder a esta questão de pesquisa, este estudo pretende analisar quais as tendências do futuro da pós-graduação no país no ano de 2030, a partir da opinião de coordenadores de cursos de pós-graduação. Para isso, será realizada uma consulta com especialistas, por meio da técnica Delphi (Wright \& Giovinazzo, 200o), os quais atuam na coordenação de cursos de pós-graduação no Brasil em diversas áreas de conhecimento.

A partir da revisão de literatura, definiram-se questões-chave para este estudo que estão distribuídas nas seguintes categorias: (I) influência da CAPES nos programas de pós-graduação; (2) possibilidade de criação de novos cursos e linhas de pesquisas; (3) alterações prováveis na modalidade de educação; (4) mudanças prováveis no padrão de qualidade da educação superior (uso de metodologias ativas; conteúdo; produção científica, tecnológica e modelo sequencial); (5) internacionalização das instituições; (6) Sala de aula da pós-graduação no futuro; (7) cursos que possuem maior possibilidade de oferta no futuro.

Após esta introdução, são apresentados os fundamentos do estudo; os procedimentos seguidos na condução da técnica Delphi, do planejamento da pesquisa à coleta de dados; os principais resultados obtidos e discussões; as considerações finais e, por fim, as referências citadas nessa pesquisa.

\section{Revisão da literatura}

\section{A pós-graduação no Brasil}

A pós-graduação no Brasil teve origem no começo dos anos I930, na Proposta do Estatuto das Universidades Brasileiras, onde Francisco Campos propunha a implantação de uma pós-graduação semelhante à educação europeia (Santos, 2003). Contudo, a oficialização da pós-graduação no país se deu com o Parecer 977, em I965, 
do Conselho Federal de Educação, que contou com a colaboração do professor Newton Sucupira, na qual deu origem a uma base de dados nacional que reúne todas as publicações da pós-graduação no país. Ele baseou-se nos padrões americanos para oficializar este nível de educação no Brasil.

\section{Prospecção de cenários futuros da pós-graduação no Brasil}

As organizações vêm a algum tempo tentando antecipar o futuro na tentativa de competir em igualdade com seus concorrentes e manter-se no mercado. Como não há a possibilidade de saber o que realmente acontecerá futuramente, pode-se fazer uma prospecção acerca do que pode vir acontecer e, assim, refletir sobre as ameaças e as oportunidades que possivelmente poderão ocorrer.

Neste sentido, desenvolver histórias de cenários sobre múltiplos futuros possíveis dá às organizações condições de enfrentarem com mais propriedade os futuros complexos e incertos, criando os fundamentos para estratégias mais criativas, abrangentes e de longo prazo (Popcorn \& Hanft, 200I).

Uma das técnicas que podem ser usadas para prospectar o futuro é o julgamento de especialistas por meio da técnica Delphi, buscando-se um consenso acerca das tendências (Wright, Silva \& Spers, 20IO). O futuro é incerto e com tantas mudanças ocorrendo a todo o momento, os especialistas podem contribuir para os estudos do futuro (Schenatto et al, 2OII). Com base em estudos prospectivos acerca do futuro podem-se realizar melhores planejamentos e refletir sobre possíveis estratégias, dando robustez à tomada de decisão (Santos et al, 2004).

Nota-se que algumas transformações no cenário atual podem influenciar no cenário da pós-graduação do futuro, como a internacionalização; o uso de tecnologias; o aumento da produção científica e tecnológica com qualidade em detrimento da quantidade com fator de impacto e melhor interação da Universidade com a sociedade. Na expectativa de que elas podem ser acentuadas ou modificadas no futuro é que se torna importante um estudo prospectivo a respeito, considerando a opinião de especialistas no tema.

A tendência da internacionalização na educação superior se dá, principalmente, em função da cooperação entre os povos e a integração efetiva da América Latina, sendo 
que a globalização e a rapidez com que as informações circulam entre as sociedades contribuem para a ocorrência desse fenômeno (Marrara, 2007). A dimensão internacional tornou-se parte integrante da pós-graduação e da pesquisa científica, fenômeno que vem ocorrendo mais fortemente nas últimas duas ou três décadas e contribuído para as notas seis e sete dos programas de pós-graduação no Brasil (Ramos, 20I8). O estudo de Prolo, Vieira, Lima e Leal (2019) discute a iniciativa do governo federal por meio do Programa Ciência Sem Fronteiras $(\mathrm{CsF})$ para a internacionalização na educação superior, entretanto, esta não tem sido suficiente para chegar ao nível que o país precisa.

Além disso, observa-se o uso intenso da tecnologia no ambiente de trabalho (Souza \& Cappellozza, 20I9), que tem sido realidade também no âmbito educacional. A literatura indica a educação a distância (EAD) ou uso de meios digitais como tendência na oferta de educação e promoção de aprendizagem. O estudo de Morilhas (2009) já observava esta tendência, indicando uma acelerada expansão da EAD, apesar de todos os desafios técnicos e pedagógicos ainda em evolução.

Nesse tema, há também, a questão de países com o interesse no intercâmbio de estudantes, com o objetivo do desenvolvimento da pesquisa interna e a oportunidade de levar para o país novos conhecimentos de acordo com Marrara (2007). A solução de problemas brasileiros e comuns da humanidade (Teles, 2005), bem como para a divulgação e promoção do conhecimento guiado por um ideal de solidariedade, são fatores que devem nortear a internacionalização da Pós-Graduação no Brasil (Marrara, 20O7).

\section{Procedimentos Metodológicos}

Para o desenvolvimento desse estudo, foi usada a técnica Delphi de julgamento de especialistas (Giovinazzo \& Fischmann, 200I). Entende-se como especialista um indivíduo ou grupo de indivíduos com treinamento adequado e familiarizado com o equipamento e processos que constituem o objeto de análise (Ayyub, 200I). A Figura I ilustra os procedimentos seguidos na aplicação da técnica. 
Figura I. Fluxo da pesquisa usando a técnica Delphi

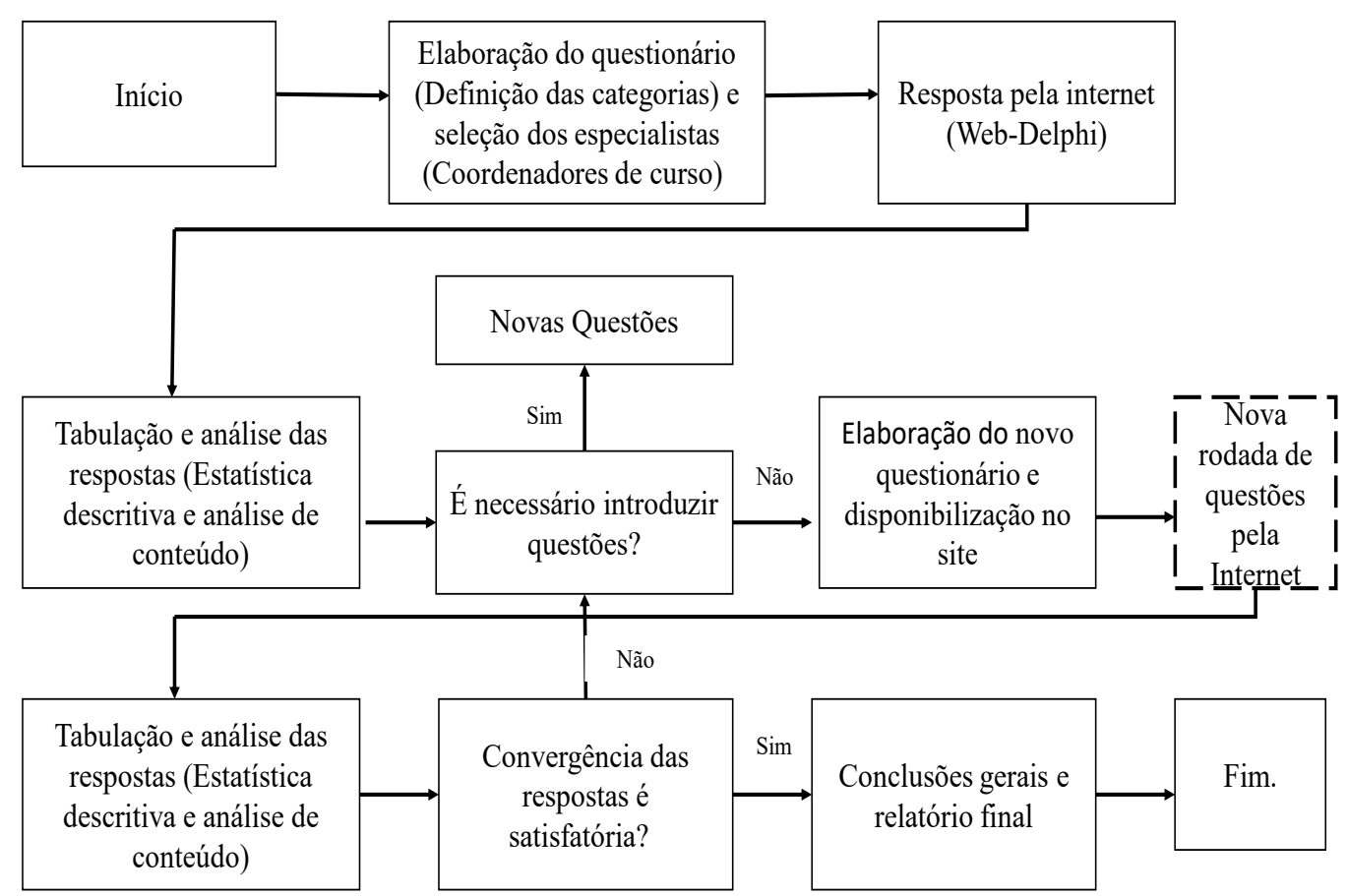

Fonte: Adaptado de Giovinazzo e Fischmann (200I).

Estabeleceu-se, inicialmente, como objetivo de pesquisa identificar qual o futuro da pós-graduação no Brasil, considerando o ano de 203o. Para atender esse objetivo, elaborou-se um questionário fundamentado nas categorias já apresentadas. Este foi disponibilizado e distribuído em meio eletrônico por meio da ferramenta Google Docs, e enviado ao endereço de correio eletrônico dos especialistas. O questionário foi composto por questões abertas e fechadas que se encontram disponíveis no Apêndice I.

Este questionário foi enviado para 30 coordenadores de pós-graduação. Destes, obteve-se o retorno de i8. O número do feedback dos respondentes na Rodada I está dentro do percentual estabelecido por Wright e Giovinazzo (2000). Segundo os autores, na primeira rodada de perguntas é comum abstenção de 30 a 50\% e na segunda rodada de 20 a $30 \%$. 
O questionário foi previamente testado com o objetivo de sanar quaisquer dúvidas na interpretação das perguntas. Enviou-se o acesso ao questionário para o email dos especialistas entre os dias or e 3 o de outubro de 2016.

Dos respondentes, 88,8\% são doutores e II,I\% especialistas, sendo um perfil considerado muito qualificado e este fato torna a pesquisa com alta qualidade (IEA-USP, 2OI3).

De acordo com Leal Junior (2OIO), o método Delphi na análise dos dados pode envolver tanto os dados qualitativos quanto os dados quantitativos. Nas questões fechadas que representa os dados quantitativos, calculou-se a frequência, a mediana e o quartil das respostas. No caso das questões abertas, que representa os dados qualitativos, fez-se análise de conteúdo (Bardin, 2OII), associando as respostas semelhantes fornecidas pelos respondentes a partir das categorias de análise apresentadas.

\section{Apresentação e Discussão dos Resultados}

As tendências que poderão compor o cenário da pós-graduação em 2030 identificadas nesse estudo, a partir da opinião dos especialistas consultados, são apresentadas e discutidas na sequência. Esses resultados foram obtidos na Rodada I da aplicação da técnica Delphi. A Figura 2 sintetiza os resultados da pesquisa.

Figura 2. Mapa Síntese do Futuro da Pós-Graduação no Brasil

\begin{tabular}{|c|c|c|}
\hline $\begin{array}{c}\text { Tendências: Programas globais, } \\
\text { parcerias interinstitucionais, } \\
\text { duplo diploma e diversidade } \\
\text { cultural }(88,9 \%)\end{array}$ & $\begin{array}{l}\text { Elevada influência da CAPES } \\
(72,2 \%) \text { em virtude da gestão } \\
\text { e determinaçào das regras. }\end{array}$ & $\begin{array}{l}\text { Internacionalizaçào: }(33,3 \%) \\
\text { maior interaçào com o exterior; } \\
(27,8 \%) \text { dupla titulaçăo; }\end{array}$ \\
\hline $\begin{array}{c}\text { Sala de aula remota com } \\
\text { presença virtual } \\
(66,7 \%)\end{array}$ & 18 coordenadores de cursos & $\begin{array}{l}\text { Futuro mais provável: } \\
\text { promissor }(72,2 \%) \text {. Foco na } \\
\text { internacionalizaçaso }\end{array}$ \\
\hline $\begin{array}{l}\text { Mudanças muito significativas } \\
(61,1 \%) . \text { Publicaçóes internacionais. } \\
\text { Necessidade de incentivo } \\
\text { governamental e ingles. }\end{array}$ & $\begin{array}{l}\text { Educaçào continuada } \\
\qquad(22 \%) \text {. Temas: } \\
\text { Nanotecnologia, } \\
\text { computaçào quântica, } \\
\text { inteligência artificial. }\end{array}$ & $\begin{array}{l}\text { Educaçào continuada ( } 22 \%) \text {. } \\
\text { Temas: Nanotecnologia, } \\
\text { computaçào quântica, } \\
\text { inteligência artificial. }\end{array}$ \\
\hline
\end{tabular}

Fonte: Resultados da Pesquisa. 
Sobre a influência do Sistema de Pontuação da CAPES, perguntou-se o nível de influência que o mesmo poderá exercer na pós-graduação (nenhuma, pouco significativa, muito significativa). Como resultado, $72,2 \%$ dos especialistas concordam que haverá muita influência. Os especialistas justificaram suas respostas em função do gerenciamento da pós-graduação ser feito pela CAPES e, por ser esta, a instituição que determina as regras deste sistema que vem priorizando produções científicas de qualidade.

Apesar dessa representatividade, identificaram-se algumas divergências de opinião nas respostas abertas, entre elas, destaca-se que segundo eles, apesar do sistema de pontuação ser eficiente e estimulante, há limitações orçamentárias nas instituições que impedem que os programas atendam às exigências da CAPES. Para outros especialistas, o sistema sequer traduz a realidade brasileira e o processo de ‘produtivismo’ não deverá perdurar no futuro.

Sobre o padrão de qualidade da pós-graduação, perguntaram-se quais mudanças poderão ocorrer no futuro (não haverá, pouco significativa, muito significativa e radical). 6I,I\% dos especialistas concordam que ocorrerão mudanças muito significativas no padrão de qualidade da pós-graduação no Brasil. A busca por publicações em periódicos internacionais com consequente aumento da qualidade no impacto dos artigos justifica tais mudanças. Os especialistas também alertam para a necessidade de investimento do governo e a necessidade do domínio do idioma inglês para que as mudanças se concretizem no futuro.

Sobre os programas de pós-graduação no futuro, perguntou-se aos especialistas qual futuro deverá ser mais provável nos próximos I5 anos (sem futuro, pouco promissor, promissor, revolução). $7^{2,2} \%$ dos especialistas concordam que haverá um futuro promissor. Identificou-se que a internacionalização poderá ser o fator que impulsionará esta mudança.

Foi solicitado aos respondentes que selecionassem seis tendências que serão mais prováveis de ocorrer na pós-graduação no futuro, considerando o ano de 2030 (serão programas globais; buscarão grupos de estudantes mais homogêneos; serão programas com matriz curricular mais flexível; reduzirão o tempo de integralização no currículo; usarão de forma mais intensa métodos ativos centrados no participante; 
usarão métodos educacionais personalizados com foco no desenvolvimento de projetos; negócios e atividades voltadas para os estudantes; serão programas de pós-graduação voltados focados em desenvolver a liderança, etc.). 88,9\% dos respondentes concordam que os programas de pós-graduação do futuro serão globais e buscarão maior internacionalização e parcerias interinstitucionais para a oferta de duplo diploma e privilegiarão a diversidade cultural. Poderá haver, segundo os especialistas, programas que atenderão interesses privados no futuro.

Nota-se que o idioma inglês passa a ter uma importância ainda maior no cenário da pós-graduação do futuro. Assim, nota-se que as respostas dos especialistas estão de acordo com o que é defendido por Marrara (2007), a respeito da oferta de duplodiploma com validade em duas instituições, sendo esta uma tendência identificada.

Tendo-se em vista mudanças já no cenário atual da educação no Brasil, perguntou-se como poderá ser a sala de aula do futuro da pós-graduação, considerando o ano de 2030, (física tradicional, física interativa, remota tradicional, remota com presença virtual, etc.). 66,7\% dos entrevistados concordam que os especialistas concordam que o modelo de sala de aula predominante no futuro poderá ser remota com presença virtual. Porém, é preciso considerar que cada área de conhecimento é peculiar, e em algumas áreas pode ser que essa não seja a única alternativa de interação entre professor-aluno e aluno-aluno no contexto da pós-graduação no futuro.

Sobre a expansão da pós-graduação no futuro, perguntou-se aos especialistas se o crescimento continuará conforme já verificado entre 2007 e 20I7. 50\% dos especialistas concordam que a expansão no número de matrículas da pós-graduação deverá continuar em 2030. E o crescimento pode ser confirmado pelo atendimento de metas do Sistema Nacional de Pós-Graduação do Brasil, que recomenda a formação de mestres e doutores para atender a demanda no país no magistério superior, bem como a continuidade nas pesquisas.

Sobre a internacionalização dos programas de pós-graduação em 203O, perguntou-se qual opção mais se alinha à internacionalização (participação de alunos em congressos no exterior; publicação em periódicos internacionais; interação dos alunos de programas nacionais com alunos de programas do exterior). $33,3 \%$ dos especialistas concordam que deverá haver maior interação dos alunos dos programas 
de pós-graduação nacional com os do exterior, seguido de maior ênfase na dupla titulação (27,8\%), além de receber docentes e alunos visitantes de outros países (II,I\%).

Sobre os cursos de pós-graduação do futuro, perguntaram-se aos especialistas quais poderão ser os cursos mais procurados no futuro (e-commerce, bionformação, educação continuada, telemedicina, network, geomicrobiologia, diversidade, web producer e história corporativa). $22,2 \%$ dos especialistas indicaram a educação continuada como sendo um curso que poderá ser o mais procurado no futuro. Os especialistas acreditam também que haverá cursos sobre as temáticas "nanotecnologia”, “computação quântica" e "inteligência artificial”.

\section{Considerações Finais}

Sugere-se que em pesquisas futuras o número de especialistas seja ampliado, bem como a quantidade de rodadas da técnica Delphi e, assim, verificar se há a necessidade de correção quanto às tendências da pós-graduação no futuro na opinião de especialistas em relação ao que já foi verificado na primeira rodada da técnica Delphi.

Este estudo teve como objetivo analisar as tendências da pós-graduação no futuro, considerando o ano de 2030, na opinião de coordenadores de pós-graduação no Brasil. O objetivo do estudo foi atendido na primeira rodada de aplicação da técnica Delphi. Conclui-se que a internacionalização das instituições de educação é uma tendência do futuro em função da globalização que já é uma realidade. Daí a necessidade do domínio do idioma inglês por parte da comunidade acadêmica.

A pós-graduação continuará em expansão e para que sejam realizadas produções cada vez melhores e com maior impacto é imprescindível o investimento governamental. Segundo os especialistas o atendimento dos critérios estabelecidos pela CAPES seria mais bem atendidos com recursos orçamentários que pudessem arcar com os custos das pesquisas.

O Sistema de Pontuação exercerá influência muito significativa no futuro da pós-graduação no Brasil, considerando que o padrão de qualidade dos cursos depende da avaliação da CAPES. Neste sentido, ocorrerão mudanças muito significativas para que o padrão Qualis seja continuado. É consenso entre os especialistas que a sala de aula do futuro será remota com presença virtual, onde todos estarão reunidos 
virtualmente ao mesmo tempo, sem estarem necessariamente no mesmo espaço físico.

Esta é uma realidade que cada vez mais se consolida e que o resultado do estudo corrobora.

Os resultados apresentados poderão ser úteis a CAPES no planejamento da formulação de políticas públicas em relação à pós-graduação. Assim, como se espera que o governo também possa usufruir da opinião dos especialistas neste tema.

\section{Referèncias}

Ayyub, B. M. Elicitation of Expert Opinions for Uncertainty and Risks. CRC.

Bardin, L. (2OII). Análise de conteúdo. 3. reimp. Lisboa: Edições, v. 7 O.

Braga, L. D. (2OI2). O uso do xadrez como recurso didático para aplicação dos jogos de empresas. Volta Redonda: UFF. Trabalho de Conclusão de Curso de Graduação em Administração, Universidade Federal Fluminense - UFF. Volta Redonda.

CAPES, Coordenação de Aperfeiçoamento de Pessoal de Nível Superior. (1965). Parecer 977. Disponível em https://www.capes.gov.br/images/stories/ download/legislacao/Parecer_CESU_977_I965.pdf. Acesso em: 26 de setembro de 2016.

CAPES, Coordenação de Aperfeiçoamento de Pessoal de Nível Superior. (2008). História e missão da CAPES. Disponível em: http://www.capes.gov.br/pt/ historia-e-missao. Acesso em: 27 de Setembro de 2016.

CAPES, Coordenação de Aperfeiçoamento de Pessoal de Nível Superior (20I4). Disponível em: http://www.capes.gov.br/36-noticias/r647. Acesso em 30 de Outubro de $20 \mathrm{O} 6$.

Dantas, F. (2004). Responsabilidade social e pós-graduação no Brasil: ideias para avaliação. RBPG, v.I, n.2, p. I62-I63.

Furtado, H.L, \& Hostins, R.C.L. (2014). Avaliação da pós-graduação no Brasil. Rev. Educação PUC-Campinas, Campinas, p.ı8.

GEOCAPES, Sistema de Informações Georreferenciadas da CAPES (2015). Disponível em: http://geocapes.capes.gov.br. Acesso em: 27 de Outubro de 2016.

Giovinazzo, R. A., \& Fischmann, A. A. (200I). Delphi eletrônico: Uma experiência de utilização da metodologia de pesquisa e seu potencial de abrangência regional. XIV Congresso Latino-americano de Estratégia, São Paulo.

IEA-USP, Instituto de Estudos Avançados da Universidade de São Paulo. (2OI3). Disponível em: http://www.iea.usp.br/pesquisa/nucleos-de-apoio-apesquisa/observatorio-inovacao-competitividade. Acesso em o4 de Novembro de 2016.

Junior, I. C. L. (2OIO). Método de escolha modal para transporte de produtos perigosos com base em medidas de ecoeficiência. Tese (doutorado) - Programa de Pós- 
graduação em Engenharia de Transportes, COPPE. Universidade Federal do Rio de Janeiro - UFRJ. Rio de Janeiro.

Marrara, T. (2007). Internacionalização da Pós-Graduação: Objetivos, formas e avaliação. RBPG, Brasília, v.4, n.8, p. 245-262.

Morilhas, L. J. (2009). The expansion of distance education (ODL) brasileiro in Higher education: trends for the start of the next decade. Future Studies Research Journal, I(I), pp. 66-88.

Popcorn, Faith, \& Hanft, A. (2OOI). O dicionário do futuro: as tendências e expressões que definirão nosso comportamento. Rio de Janeiro: Campus, 200I. Press LLC, London.

Prolo, I.; Vieira, R. C.; Lima, M C. \& Leal, F. G. (2OI9). Internacionalização das universidades brasileiras - contribuições do programa ciência sem fronteiras. Administração: Ensino e Pesquisa, Rio de Janeiro, 2O(2), 319-36I.

Ramos, M. Y. (20I8). Internacionalização da pós-graduação no Brasil: lógica e mecanismos. Educação \& Pesquisa, São Paulo, 44, eI6I579, doi: http://dx.doi.org/IO.I590/Si5I7-970220I706I6I579

Santos, C. M. (2003). Tradições e contradições da Pós Graduação no Brasil. Educação e Sociedade, Campinas, v. 24, n.83, p. 627-64I.

Santos, M. M, Coelho, G. M., Santos, D. M., \& Filho, L. F. (2004). Prospecção de tecnologias de futuro: Métodos, técnicas e abordagens. Parcerias Estratégicas, n. I9, p. I89-229.

Schenatto, F. J. A., Polacinski, E., Abreu, A.F, \& Abreu, P. F. (2OII). Análise crítica dos estudos do futuro: Uma abordagem a partir do resgate histórico e conceitual do tema. Gest. Prod., São Carlos, v. I8, n. 4, p. 739-754.

Souza, R. L., \& Cappellozza, A. (2019). Os Efeitos dos Estilos de Liderança e Vício em Internet no Tecnoestresse. Revista Administração em Diálogo - RAD, 2I(I), 3962.

Teles. A. C. T. O. (2005). Internacionalização acadêmica: Um percurso de desafios. Revista da UFG, v.7, n.2, p. OI-O5.

Wright, J. T. C., \& Giovinazzo, R. A. (200o). Delphi - Uma ferramenta de apoio ao planejamento prospectivo. Caderno de Pesquisa em Administração, V OI, $\mathrm{n}^{\circ}$ I2, São Paulo.

Wright, J.T, Silva, A. T. B., \& Spers, R. G. (2OIO). O mercado de trabalho no futuro: Uma discussão sobre profissões inovadoras, empreendedorismo e tendências para 2020. Revista de Administração e Inovação, São Paulo, v. 7, n. 3, p. I74-I97. 
Apêndice - Questionário Delphi - O Futuro da Pós-Graduação no Brasil em 2030

I ${ }^{\text {a }}$ Rodada

Você está sendo convidado para participar de uma pesquisa cujo tema é “O futuro da pósgraduação no Brasil em 2030”. Acreditamos que sua ampla experiência acadêmica poderá contribuir muito para o desenvolvimento desta pesquisa. De 2007 a 2OI7, observou-se um crescimento expressivo no número de alunos matriculados nos cursos de mestrado e doutorado no país, bem como dos programas de pós-graduação. Nesse mesmo período, cresceu também o número de publicações. Assim, queremos saber: qual será o futuro da pós-graduação no Brasil em 203O, na opinião de especialistas?

Considerando o ano de 2030, gostaríamos de obter a sua resposta ao seguinte questionário que usa a técnica Delphi. O questionário exige cerca de 6 minutos para responder.

1) Preencha com seus dados

\begin{tabular}{|l|l|}
\hline Nome: & Idade: \\
\hline E-mail: & Tempo de Experiência: \\
\hline Cargo AtualEmpresa: & \\
\hline Maior escolaridade: ( ) Graduação ( ) Especialização ( ) Mestrado ( ) Doutorado \\
\hline Área de formação (Principal):
\end{tabular}

1. Considerando o ano de 2030, como você observa a influência do sistema de pontuação da CAPES na Pós-Graduação no Brasil? Escolha apenas 1 alternativa.

\begin{tabular}{|l|l|l|}
\hline Escolha 1 & \multicolumn{1}{|c|}{ Característica } & Justifique sua escolha \\
\hline & Nenhuma influência & \\
\hline & Influência pouco significativa & \\
\hline & Influência muito significativa & \\
\hline
\end{tabular}

Se você acredita que outra característica, além das listadas acima, será necessária ao sistema de pontuação da CAPES na Pós-Graduação no Brasil do futuro, escreva abaixo: 
2. Qual ou quais as prováveis mudanças no padrão de qualidade da Pós-Graduação no Brasil considerando o ano de 2030?

\begin{tabular}{|l|l|l|}
\hline Escolha 1 & \multicolumn{1}{|c|}{ Característica } & Justifique sua escolha \\
\hline & Não haverá mudanças & \\
\hline & Mudanças pouco significativas & \\
\hline & Mudanças muito significativas & \\
\hline & Mudanças radicais & \\
\hline
\end{tabular}

Se você acredita que outra característica, além das listadas acima, será necessária ao padrão de qualidade na Pós-Graduação no Brasil do futuro, escreva abaixo:

3. Você acredita que, nos próximos 15 anos, os Programas de Pós-Graduação no Brasil deverão promover mudanças? Qual futuro você acredita ser mais provável para a PósGraduação no Brasil? Escolha apenas 1 alternativa.

\begin{tabular}{|l|l|l|l|}
\hline Escolha 1 & \multicolumn{1}{|c|}{ Futuro } & \multicolumn{1}{|c|}{ Descrição } & Justifique sua resposta \\
\hline & Sem futuro & $\begin{array}{l}\text { Não ocorrerão } \\
\text { mudanças. }\end{array}$ & \\
\hline & Pouco promissor & $\begin{array}{l}\text { Ocorrerão mudanças } \\
\text { poucos significativas. }\end{array}$ & \\
\hline & Promissor & $\begin{array}{l}\text { Ocorrerão mudanças } \\
\text { significativas. }\end{array}$ & \\
\hline & Revolução & $\begin{array}{l}\text { Ocorrerão mudanças } \\
\text { radicais. }\end{array}$ & \\
\hline
\end{tabular}


4. Considerando o ano de 2030, escolha apenas 6 tendências que você acredita que serão mais prováveis de ocorrer na Pós-Graduação no Brasil do futuro?

\begin{tabular}{|c|c|c|}
\hline Escolha 6 & Característica & Justifique sua escolha \\
\hline & $\begin{array}{c}\text { Serão Programas de Pós-Graduação globais, buscarão maior } \\
\text { institucionalização e parcerias interinstitucionais para a oferta de } \\
\text { duplos diplomas e privilegiarão a diversidade cultural. }\end{array}$ & \\
\hline & $\begin{array}{l}\text { Buscarão grupos de estudantes mais homogêneos e estimularão de } \\
\text { forma intensa a troca de experiência e um poderoso networking. }\end{array}$ & \\
\hline & $\begin{array}{l}\text { Serão Programas de Pós-Graduação com matriz curricular mais } \\
\text { flexível. Os alunos poderão personalizar o conteúdo e a sequência } \\
\text { dos mesmos. }\end{array}$ & \\
\hline & $\begin{array}{l}\text { Reduzirão o tempo de integralização do currículo (tempo de } \\
\text { formação, que atualmente é de } 24 \text { meses para o Mestrado e } 48 \\
\text { meses para o Doutorado). }\end{array}$ & \\
\hline & $\begin{array}{c}\text { Usarão de forma mais intensa métodos ativos centrados no } \\
\text { participante para que os alunos possam praticar teorias, aprender } \\
\text { fazendo e vivenciar experiências próximas da realidade. }\end{array}$ & \\
\hline & $\begin{array}{c}\text { Usarão métodos eduacionais personalizados com foco no } \\
\text { desenvolvimento de projetos, negócios e atividades voltadas para } \\
\text { o interesse dos estudantes. }\end{array}$ & \\
\hline & $\begin{array}{c}\text { Serão Programas focados em desenvolver a liderança por meio de } \\
\text { métodos eduacionais que envolvem intensamente o trabalho } \\
\text { colaborativo e em equipe. }\end{array}$ & \\
\hline & $\begin{array}{l}\text { Serão Programas de Pós-Graduação voltados para o estímulo da } \\
\text { criatividade, da inovação e do empreendedorismo. }\end{array}$ & \\
\hline & $\begin{array}{l}\text { Serão Programas com foco no ensino da produtividade, eficiência } \\
\text { e administração do tempo e priorização de tarefas. }\end{array}$ & \\
\hline & $\begin{array}{c}\text { Serão Programas de Pós-Graduação que interagem intensamente } \\
\text { com as empresas e outras organizações para realizar projetos e } \\
\text { pesquisas. }\end{array}$ & \\
\hline & $\begin{array}{c}\text { Serão Programas que desenvolverão parcerias com grandes } \\
\text { empresas para oferecer mentoria de conselheiros com muitos anos } \\
\text { de experiência aos estudantes. }\end{array}$ & \\
\hline & $\begin{array}{c}\text { Desenvolverão melhor a noção das realidades organizacionais no } \\
\text { âmbito do qual os estudantes atuam. Serão mais hábeis em trazer } \\
\text { essas realidades para a sala de aula. }\end{array}$ & \\
\hline & $\begin{array}{c}\text { Buscarão maior equilibrio entre "saber" (conhecimento anlítico), } \\
\text { "fazer" (desenvolvimento de habilidades) e "ser" (senso de } \\
\text { propósito e identidade). }\end{array}$ & \\
\hline & $\begin{array}{l}\text { Serão Programas mais conectados com o mundo virtual. Farão } \\
\text { uso intenso da Internet para oferecer conteúdo (e-books, } \\
\text { vídeoaulas, etc.) e oferecer aulas online em tempo real. }\end{array}$ & \\
\hline
\end{tabular}

Se você acredita que outra tendência, além das listadas, será mais provável de ocorrer nos Programas de Pós-Graduação no Brasil do futuro, escreva-a abaixo e justifique a sua resposta: 
5. Considerando o ano de 2030, escolha 2 alternativas que descreve como será a sala de aula predominante na Pós-Graduação do futuro.

\begin{tabular}{|c|c|c|c|}
\hline Escolha 2 & Sala de Aula & Descrição & Justifique sua escolha \\
\hline & $\begin{array}{c}\text { Física } \\
\text { Tradicional }\end{array}$ & $\begin{array}{c}\text { Salas de aula física em formato tradicional. Uso } \\
\text { predominante de aulas expositivas e seminários. } \\
\text { Mesas e cadeiras dispostas com centro no } \\
\text { professor. }\end{array}$ & \\
\hline & $\begin{array}{c}\text { Física } \\
\text { Interativa }\end{array}$ & $\begin{array}{l}\text { Salas de aula física com muitas pessoas conectadas } \\
\text { em rede ao mesmo tempo. Um ambiente interativo } \\
\text { onde o conhecimento coletivo e individual circula } \\
\text { de forma simples e instantânea com o uso de alta }\end{array}$ & \\
\hline & $\begin{array}{l}\text { Física com } \\
\text { Foco no } \\
\text { Participante }\end{array}$ & $\begin{array}{c}\text { Salas de aula projetadas para promover a } \\
\text { aprendizagem ativa (aprender fazendo), em que } \\
\text { atividades coletivas e o trabalho em equipe serão } \\
\text { indispensáveis. }\end{array}$ & \\
\hline & $\begin{array}{c}\text { Física no } \\
\text { Campo }\end{array}$ & $\begin{array}{c}\text { Salas de aula em que parte dela ocorrerá dentro } \\
\text { das organizações reais em que será possível fazer } \\
\text { projetos e promover aprendizado por meio da } \\
\text { vivência e alta troca de experiência. }\end{array}$ & \\
\hline & $\begin{array}{c}\text { Remota } \\
\text { Tradicional }\end{array}$ & $\begin{array}{l}\text { Salas de aula serão repositórios de conteúdo. Os } \\
\text { estudantes terão acesso virtual para adquirir o } \\
\text { material e estudar de forma autônoma quando e } \\
\text { onde desejar. }\end{array}$ & \\
\hline & $\begin{array}{l}\text { Remota } \\
\text { com } \\
\text { Presença } \\
\text { Virtual }\end{array}$ & $\begin{array}{l}\text { Salas de aula em que todos estarão reunidos } \\
\text { virtualmente ao mesmo tempo, sem estarem } \\
\text { necessariamente no mesmo espaço fisico. }\end{array}$ & \\
\hline & \begin{tabular}{|} 
Remotas \\
com foco \\
no \\
participante
\end{tabular} & $\begin{array}{l}\text { Salas de aula projetadas para promover a } \\
\text { aprendizagem ativa (aprender fazendo) em } \\
\text { ambiente virtual em que todos se comunicam e } \\
\text { interagem ao mesmo tempo. }\end{array}$ & \\
\hline
\end{tabular}

Se você acredita que a sala de aula da Pós-Graduação do futuro será de outra forma, além da que você já selecionou, descreva abaixo: 
6. Segundo a GEOCAPES (2005), o sistema de georreferenciamento da CAPES, houve um crescimento de 96\% no número de alunos matriculados nos cursos de Pós-Graduação Stricto Sensu no Brasil no período de 2007 a 2017. O SR(a) pensa que essa expansão permanecerá nos próximos 15 anos?

\begin{tabular}{|l|l|l|}
\hline Escolha 1 & \multicolumn{1}{|c|}{ Característica } & Justifique sua escolha \\
\hline $\begin{array}{l}\text { O crescimento no número de alunos } \\
\text { matriculados não continuará de } \\
\text { forma expressiva como verificado } \\
\text { no período compreendido entre } \\
2006 \text { a } 2015 .\end{array}$ & \\
\hline $\begin{array}{l}\text { Haverá pouco crescimento no } \\
\text { número de matriculas em função de } \\
\text { fatores políticos }\end{array}$ & \\
\hline $\begin{array}{l}\text { O crescimento continuará de forma } \\
\text { contínua como já verificado no } \\
\text { período compreendido entre 2006 a } \\
2015 .\end{array}$ \\
\hline
\end{tabular}

Se você acredita a expansão da Pós-Graduação do futuro será de outra forma, além da que você já selecionou, descreva abaixo: 
8. Quais os cursos de Pós-Graduação o(a) SR(a) pensa que serão mais procurados em 2030 ?

\begin{tabular}{|c|c|c|}
\hline Escolha 1 & Área/Característica & Justifique sua escolha \\
\hline & 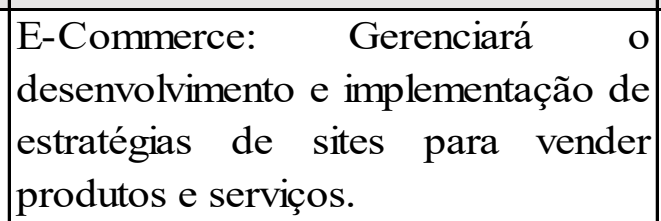 & \\
\hline & \begin{tabular}{|lrr} 
Bioinformação: & Trabalhará & com \\
informações & genéticas e faz & ponte \\
com o $\quad$ desenvolvimento & de \\
medicamentos e técnicas clínicas.
\end{tabular} & \\
\hline & 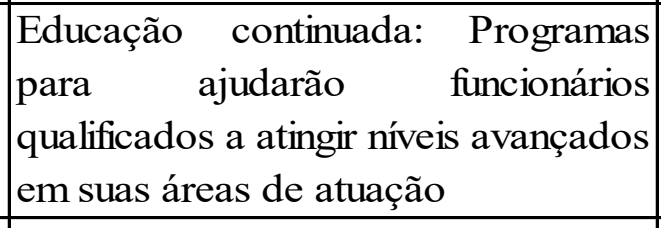 & \\
\hline & $\begin{array}{l}\text { Telemedicina: Oferecerá tratamento } \\
\text { médico e diagnóstico para pessoas } \\
\text { em áreas remotas. }\end{array}$ & \\
\hline & $\begin{array}{l}\text { Network: Pesquisa o fluxo de poder } \\
\text { dentro de uma companhia }\end{array}$ & \\
\hline & \begin{tabular}{|l|l|} 
Geomicrobiologia: Usará a geologia, \\
ciências do meio ambiente e \\
microbiologia para estudar \\
microorganismos
\end{tabular} & \\
\hline & $\begin{array}{l}\text { Diversidade: Irá certificar que não } \\
\text { haverá tratamento diferenciado em } \\
\text { diversos setores das organizações }\end{array}$ & \\
\hline & $\begin{array}{l}\text { Web Producer: Desenvolverá, } \\
\text { implementará e manterá aplicações } \\
\text { da web para sites de e-commerce }\end{array}$ & \\
\hline & $\begin{array}{|llr|}\text { História } & \text { corporativa: } & \text { Resgatará } \\
\text { projetos, } & \text { programas, } & \text { problemas, } \\
\text { soluções } & \text { e resultados } & \text { de uma } \\
\text { organização. } & & \\
\end{array}$ & \\
\hline
\end{tabular}

Se você acredita que há outros cursos que irão compor os Programas de Pós-Graduação do Brasil num futuro considerando o ano de 2030, além da que você já selecionou, descreva abaixo e justifique a sua resposta: 